\title{
Geographical Analysis and Mapping of Road Traffic Accident Occurrence and Severity in Nigeria
}

\author{
Emmanuel Dada ${ }^{1}$, Adebola Olaoluwa Hassan ${ }^{2}$, Dada Victoria Tobi ${ }^{3}$ \\ ${ }^{1}$ Department of Geography and Planning Sciences, Adekunle Ajasin University, Akungba Akoko, Nigeria \\ ${ }^{2}$ Department of Photogrammetry and Geoinformatics, Stuttgart University of Applied Sciences, Stuttgart, Germany \\ ${ }^{3}$ Institute of Ecology and Environmental Studies, Obafemi Awolowo University, Ile-Ife, Nigeria
}

Email address:

vissitemma@gmail.com (E. Dada), hassanadebola89@gmail.com (A. O. Hassan), tobiade89@gmail.com (D. V. Tobi)

\section{To cite this article:}

Emmanuel Dada, Adebola Olaoluwa Hassan, Dada Victoria Tobi. Geographical Analysis and Mapping of Road Traffic Accident Occurrence and Severity in Nigeria. International Journal of Science and Qualitative Analysis. Vol. 7, No. 1, 2021, pp. 14-20.

doi: $10.11648 /$ j.ijsqa.20210701.13

Received: May 8, 2021; Accepted: May 24, 2021; Published: June 22, 2021

\begin{abstract}
The advantage of automobile transportation does not overcome its shortcomings. Foremost among these is road traffic accident which is serious cause of death in the whole world today. This study examined and mapped rate of reported cases of road accidents across the 36 States and the federal capital of Nigeria between 2013 and 2015. Data acquired from Federal Bureau of Statistics was analysed using descriptive and inferential statistical methods. Bar charts, graphs, dot map and thematic map were prepared to depict the spatial distribution of the occurrences and fatality classification while regression analysis was used to predict the future situation of road accident in Nigeria. Results showed that; highest rate of accidents $36.9 \%$ occurred in the year 2013 with 5,539 deaths. Ogun State recorded highest number of accidents with 9.7\% in 2013, Lagos State with 15.4\% in 2014 and Ogun State with $6.1 \%$ in 2015 which can be attributed to the strategic position of these two States as the gate ways to Nigeria economy. The regression result shows the strong positive relationship between numbers of recorded cases of road accident and death from road traffic accident with regression $R$ value of 0.78 and $R^{2}$ of 0.61 respectively.
\end{abstract}

Keywords: Road Traffic, Accident, Reported Cases, Fatality

\section{Introduction}

The quest for the faster movement of people and goods from one place to the other gave birth to the invention of automobile as the major carrier of road transport dated back to 1769 [4]. Thus, the invention of automobile engine has experienced several improvements at different period of time to improve its service delivery in terms of flexibility of the mode, speed, and conveniences. This advancement in the automobile technology is not only advantageous to the humanity but of course have great demerits foremost among which is road accident which is one of the serious cause of death throughout the world $[1,3]$.

International Road Federation, Geneva centre [10], reported approximately 2.4 million people had died in road accident in the world with the annual record rate of 1.3 million deaths and daily record of 3,000 deaths. This figure is excluding vast number of automobile accident deaths without record. The worst scenario of death and sustained injuries owing to road traffic accident occur in the low income countries of the world as a result of deplorable road conditions and vehicles that plight these roads and noncompliance to the traffic rules by the road users $[6,10]$.

Tawia Addo-Ashong of World Bank Global Safety Facility coordinator noted that 1.2 million people die annually from road traffic accidents in the third world countries. Hence, most of the countries in Africa including Nigeria are in this category and therefore are worst hit by fatal road accidents. The research conducted by [5] revealed that fatality of road accidents in Africa are in multiple of 10 fold to more than 100fold that of United States of America. [9] Noted in his study that Africa has an average rate of 28.3 per 100,000 population road traffic mortality in comparison with 11 in Europe and general average of deaths per 100,000 populations.

Nigeria with the population of almost 200 million, people has a high level of vehicular population of over 7.6 million having total road length of about 194,000kilometres 
including the three tiers of Federal, State, and Local government roads [7]. This is responsible for the high population-road-ratio of 860 persons per square kilometre thereby undoubtedly put great pressure on the number of available roads which increase the rate of traffic accidents in Nigeria [7, 16].

In a survey of road traffic accidents involving 193 countries of the world revealed Nigeria as the second highest countries [17]. Hence, three quarter of all accidents on Nigerian roads are fatal [13]. This has however prompted the World Health Organisation in 2013 to conduct a survey of death rate in Nigeria as the most vulnerable country in Africa with death rate of 33.7 persons per 100,000 populations annually. This sub-set of United Nations reported that one in every four road accidents death in Africa occurred in Nigeria.

Thus, the causes of road traffic accidents in Nigeria can be stratified into: human, mechanical and environmental factors with the human factor accounted for almost $90 \%$ while other two factors contributed the remaining $10 \%[8,16]$.

Motivation of the Study

The high number of lives lost to road traffic accidents in Nigeria as the highest in African continent is a serious concern that deserves urgent action from various stakeholders involve in transportation and disaster management [17]. Recently, this is next to the number of lives lost to Boko Haram insurgency attacked in Nigeria recently. This however required urgent and collective efforts of the researchers, law enforcement agencies, disaster management team and the road users to find means to drastically reduce the number of lives lost to road accidents in Nigeria to at least world average standard of 18 deaths per 100,000 from the present situation of over 33 deaths per 100,000 [17]. Hence, if this is not checked, there is every tendency of increase in the cases of fatal accidents in Nigeria due to increase in the number of vehicles on the roads without commensurate increase in the number of roads as well as improvement in the available road conditions and other facilities. This research is however important to pursue the course of ameliorating fatal road crashes by mapping and classifying the states in Nigeria based on their rate of crashes occurrence. Though, accident is unavoidable but its rate of occurrence can be ameliorated to the lowest minimum by decentralized monitoring road disaster management teams to the state and local governments because of the absence of locational data in Nigeria due to poor geospatial technological development for accurate or exact locational information.

\section{Literature Review}

Road traffic accident is caused by several factors which are classified into three categories including human factor, mechanical factor and lastly environmental factor. According to [2], human factors alone made up $80 \%$ of the causes of road traffic accident in Nigeria and the very important components of this factor are driver, pedestrian, law enforcement agent and the automobile engineer. Larger proportion of drivers on Nigerian's routes are reckless because they are under the influence of substance. Mechanical factor however constitutes all the components of automobile engine which could be dysfunctional at any time while on the road despite daily or periodic check either by road safety officer or by the vehicle owners before embarking on any journey. The most common among the mechanical factors include brake failure, burst tyres, engine failure; fake spare parts among others constitute serious cause of road traffic accident in Nigeria. Environmental factor in this context refers to the climatic and topographical factors which constitute another cause of road traffic accident in Nigeria. A lot of road traffic accidents in Nigeria are attributed to undulated terrain, bad weather and heavy shower that resulted to poor road conditions and other road facilities.

Developing countries suffer most losses from road traffic accident when compare to developed countries because of the current trend of urbanisation, poor state of infrastructure, and defective political economy system [14]. The ability to respond to and cope with hazards such as road traffic crash determines the impact on a country. Despite the much-received attention of this hazard, little findings is done on its geographic distribution and severity especially in the developing countries such as Nigeria [11, 15]. Unfortunately, many developing countries in Africa lack the resources to respond to road emergency needs. Hence, international organisations have been charged to support in reducing global menace of road traffic accident by providing financial and technical supports to improve safety and security in developing countries [18].

\section{Methods}

\section{Study Area}

Nigeria is located between $4^{\circ}$ to $14^{\circ} \mathrm{N}$ of the equator and between $2^{\circ}$ to $15^{\circ} \mathrm{E}$ of Greenwich Meridian in West Africa along the Atlantic Ocean Gulf of Guinea. It has the total land area of 923,768 square kilometres and $853 \mathrm{~km}$ coastline. Nigeria shares boundary with Benin Republic to the west, Cameroun and Chad to the east and Niger Republic to the North. The country has 36 states with the Federal capital territory in Abuja. The terrain of Nigeria includes lowlands that ascend up into the hills in the south, plateaus in the central, mountainous in the southeast and plains in the north. It has an estimated population of about 200 million people [12].

\section{Methods}

This research made use of both primary and secondary data. The primary data includes focused group discussion with Federal Road Safety Commission (FRSC), Vehicular Inspection Officers (VIO), National Union of Road Transport Workers (NURTW) and other major road users in some selected units and locations across all the regions of Nigeria. Secondary data used for this research were accessed from Federal Bureau of Statistics data bank for the compiled reported cases of road traffic accident. Additional data were collected from the data bank of Federal Road Safety Commission as well as their quarterly road traffic data publication called "Digest". 
The methodology employed for the data analysis include preparation of dot maps and thematic maps showing the rate of road traffic crashes in each state of Nigeria as well as classification of the states based on the fatality rate of road accident that occurred in them for better visualization. Descriptive and inferential statistical methods were also used in presenting the rate of recorded road traffic accidents in each state as well as to compare the rate in the considered years of this survey for easy and better understanding not only to the experts in this field but also to the general public because of the vitality of this findings.

ArcGIS 10.2 was used to design the dot maps and the thematic maps indicating rate of road traffic accidents and their fatality across the 36 States of the federation and Abuja the federal capital territory. Statistical Package for Social Scientists (SPSS) Descriptive statistical was employed descriptive and inferential data analyses for easy understanding and better presentation.

\section{Results and Discussion}

Data analysis, results and discussion for this research was done using descriptive and inferential statistical methods. Bar charts and time series graphs were used to present the results showing the comparative analysis of the reported cases of road traffic accidents, severities and the casualties recorded in Nigeria in 2013, 2014 and 2015 respectively. Graphs were also plot depicting the severity of the road accidents in these three years. Dot and thematic maps were also prepared showing spatial distribution of road accidents across the Nigerian States as well as their fatality classification.

Table 1. States Reported Cases of Road Traffic Accidents in Nigeria in 2013, 2014 and 2015.

\begin{tabular}{llll}
\hline State & $\mathbf{2 0 1 3}$ & $\mathbf{2 0 1 4}$ & $\mathbf{2 0 1 5}$ \\
\hline Abia & 381 & 833 & 761 \\
Adamawa & 485 & 401 & 561 \\
Akwa-Ibom & 516 & 247 & 879 \\
Anambra & 1172 & 1060 & 597 \\
Bauchi & 368 & 518 & 776 \\
Bayelsa & 356 & 421 & 869 \\
Benue & 874 & 481 & 682 \\
Borno & 138 & 280 & 410 \\
Cross River & 703 & 613 & 603 \\
Delta & 664 & 212 & 447 \\
Ebonyi & 202 & 258 & 473 \\
Edo & 1623 & 295 & 951 \\
Ekiti & 536 & 362 & 755 \\
Enugu & 1310 & 600 & 585 \\
Gombe & 328 & 547 & 714 \\
Imo & 226 & 443 & 418 \\
Jigawa & 51 & 205 & 469 \\
Kaduna & 1995 & 578 & 696 \\
Kano & 2281 & 1314 & 1274 \\
Katsina & 580 & 468 & 450 \\
Kebbi & 282 & 265 & 464 \\
Kogi & 31 & 585 & 541 \\
Kwara & 485 & 538 & 522 \\
Lagos & 1215 & 3919 & 1097 \\
Nasarawa & 308 & 261 & 829 \\
Niger & 99 & 467 & 645 \\
\hline & & &
\end{tabular}

\begin{tabular}{llll}
\hline State & $\mathbf{2 0 1 3}$ & $\mathbf{2 0 1 4}$ & $\mathbf{2 0 1 5}$ \\
\hline Ogun & 2847 & 2067 & 1513 \\
Ondo & 1029 & 675 & 943 \\
Osun & 1741 & 852 & 626 \\
Oyo & 1046 & 661 & 827 \\
Plateau & 313 & 519 & 412 \\
Rivers & 1064 & 1428 & 534 \\
Sokoto & 435 & 367 & 590 \\
Taraba & 326 & 419 & 529 \\
Yobe & 526 & 452 & 562 \\
Zamfara & 263 & 213 & 423 \\
FCT & 2695 & 1478 & 527 \\
Total & 29494 & 25427 & 24954 \\
\hline
\end{tabular}

Source: Federal Bureau of Statistics.

The table depicts the number of reported cases of road traffic accidents across the 36 states and the federal capital territory of Nigeria. It should be noted that emphasis is laid on the word "Reported" meaning there were several road accident cases that were not reported in Nigeria because there is no space technology that is focused on the monitoring this disaster which could provide both accurate numerical and locational information of the occurrence. The reasons for the States variation in the road accidents occurrence was due to variation in the length and conditions of corridors within the state, the number of connected States, economic and administrative activities, population, and terrain.

Table 2. Aggregate and severity of reported road accidents in 2013, 2014, and 2015 .

\begin{tabular}{llllllll}
\hline \multicolumn{3}{c}{ Road Accident Reported Cases } & \multicolumn{3}{c}{ Persons Involved } \\
\hline Year & Fatal & Serious & Minor & Total & Killed & Injured & Total \\
\hline 2013 & 12940 & 9074 & 7480 & 29494 & 5539 & 12372 & 17911 \\
2014 & 11665 & 7561 & 6201 & 25427 & 4430 & 12227 & 16657 \\
2015 & 11515 & 7426 & 6013 & 24954 & 5042 & 10257 & 15299 \\
\hline
\end{tabular}

Source: Federal Bureau of Statistics.

The table shows the aggregate situation of the reported cases of road traffic accident in Nigeria for the year 2013, 2014 and 2015. The situation depicts total number of reported cases of road traffic accident, fatality, serious, minor as well as total number of person involved, number of persons killed and number of persons injured. It revealed the variation in the number of recorded cases of road accident, total persons involved and the number of lives lost to this disaster in the three years of consideration in this research based on several factors mentioned above.

The bar chart in figure 1 depicts severity in the reported cases of road accidents in Nigeria with highest fatality record of $35.8 \%$ in 2013 and $31.8 \%$ as lowest in 2015 . The reason for this could be as a result of commencement of electronic driving license in 2014, strict implementation and punishment of the traffic offenders among the road users by the Federal Road Safety commission and other road traffic management agencies. This support result of Federal Road Safety Commission of Nigeria report in their monthly digest publication that gradual reduction in the road traffic accidents as part of achievement of electronic drivers' license issuance [7]. 


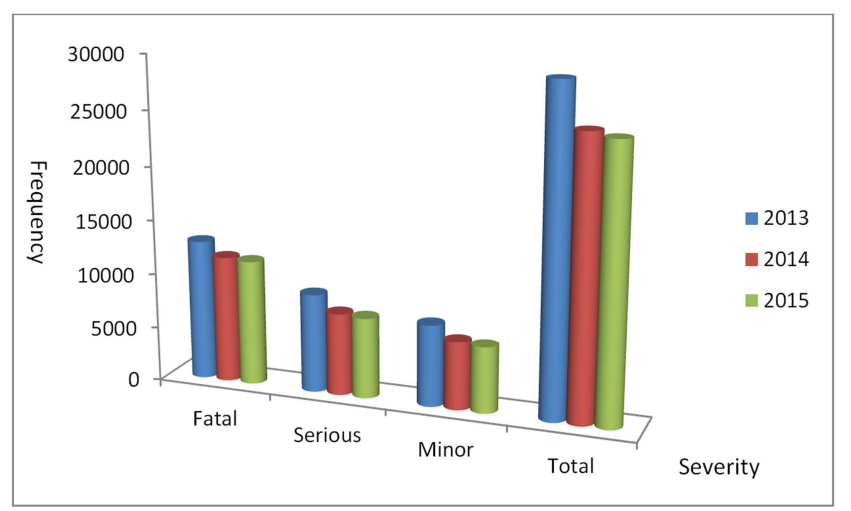

Figure 1. Severity of reported cases of road accidents in 2013, 2014, and 2015.

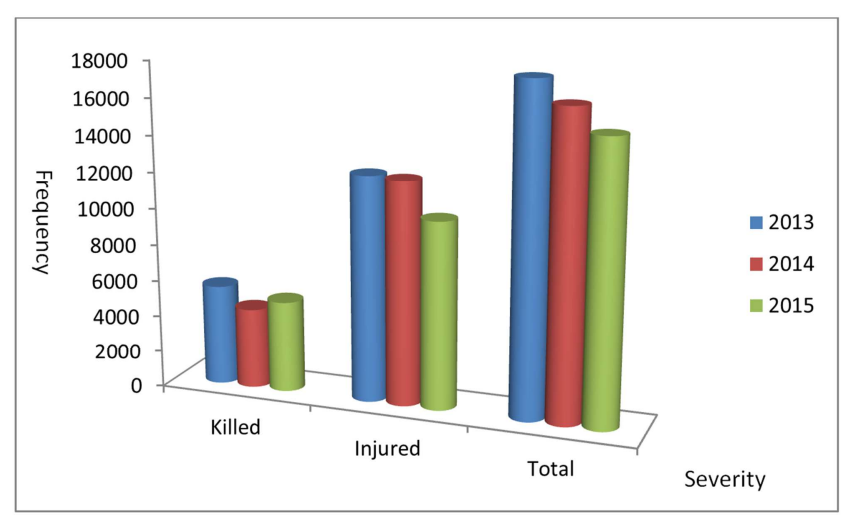

Figure 2. Persons involved in the road accidents in 2013, 2014, and 2015.

Analysis from figure 2 shows that $30.9 \%$ of the road accident victims died while $69.1 \%$ sustained various forms of injuries in 2013. In 2014, 26.6\% deaths were recorded and $73.4 \%$ sustained injury while in $2015,33.0 \%$ died and $67.0 \%$ injured. These results corroborated study of International Road Federation Report that almost $30 \%$ of road traffic accident victims in developing countries lost their lives [10]. It should be noted that the numbers of persons involved in road accidents recorded does not include the unhurt victims which constituted the highest numbers in all the years studied in this research. Hence, various reasons that could be responsible for this including human, natural and mechanical factors.

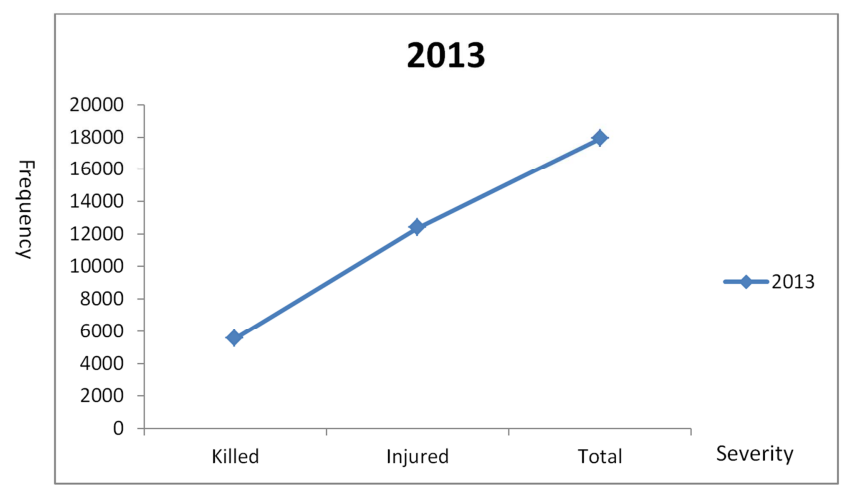

Figure 3. Persons involved in road accidents in 2013.

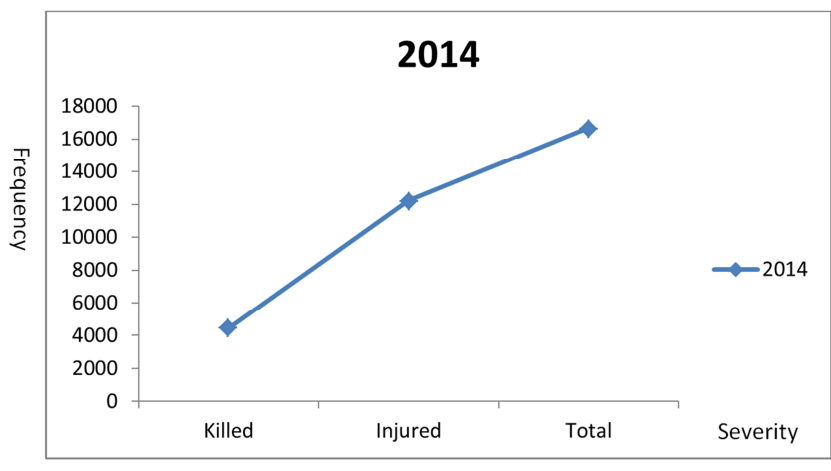

Figure 4. Persons involved in road accidents in 2014.

Result from the analysis of the road accident victims in 2013 shows that of 5539 persons died with 12372were the injured victims. It was however noted that this year experienced highest numbers of recorded road accidents among the three years of consideration for this research. This can be attributed to the non-challant attitude on the side of government and lack of sophisticated technology or equipment to track road traffic offenders as well as to confirm the authenticity of driving licences holding by automobile drivers prior to the commencement of electronic driving licence in Nigeria in 2014.

Analysis from road accident victims graph depicts gradual reduction in the number of deaths tolls from road accident when compared with 2013 with the reduction of 1,109 representing $20 \%$ death reduction from road crashes. This reduction might have been as a result of the introduction of electronics driving license process which reduced the numbers of automobiles on the road because of the cumbersome process it take to renew and acquired new driving license. This however led to reduction in the number of recorded road accidents in 2014.

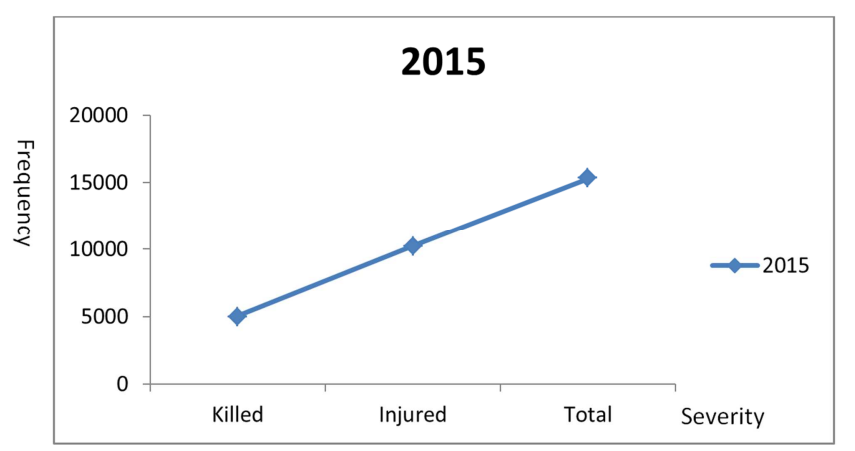

Figure 5. Persons involved in road accidents in 2015.

2015 however witnessed a slight increase with 612 persons (13.8\%) more recorded deaths in 2015 when compared to 2014. This could be as a result of the cumbersome processes in obtaining the new electronic drivers' license from the government agency which therefore increased unlicensed drivers which in turn increased the rate of road accidents fatality. 


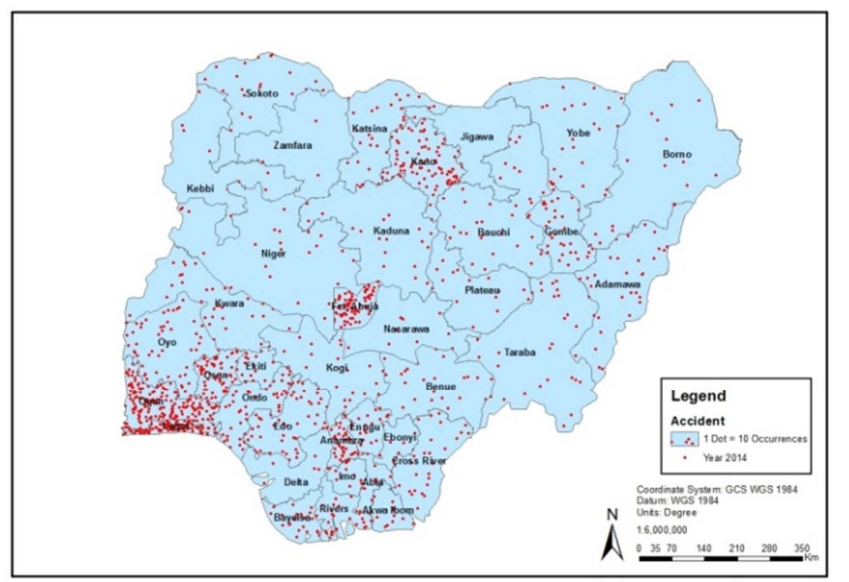

Figure 6. Dot map of road accident in Nigeria for 2013.

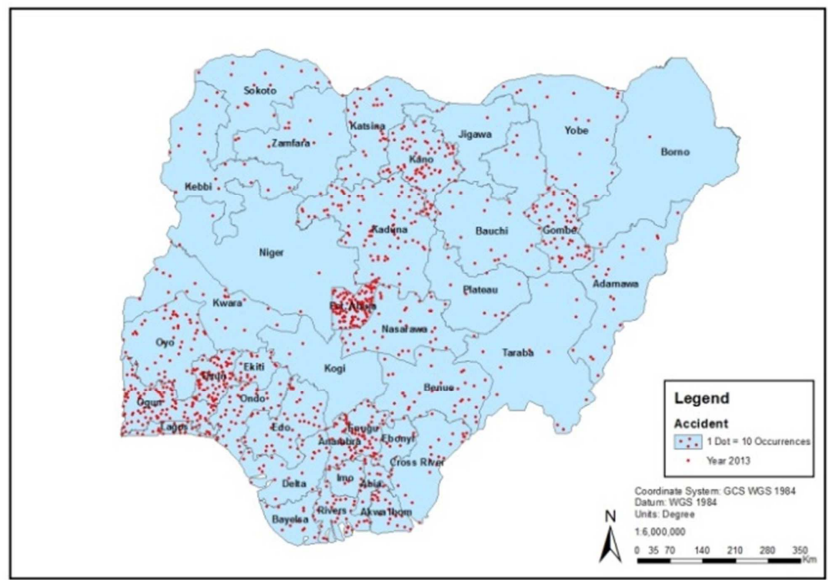

Figure 7. Dot map of road accident in Nigeria for 2014.

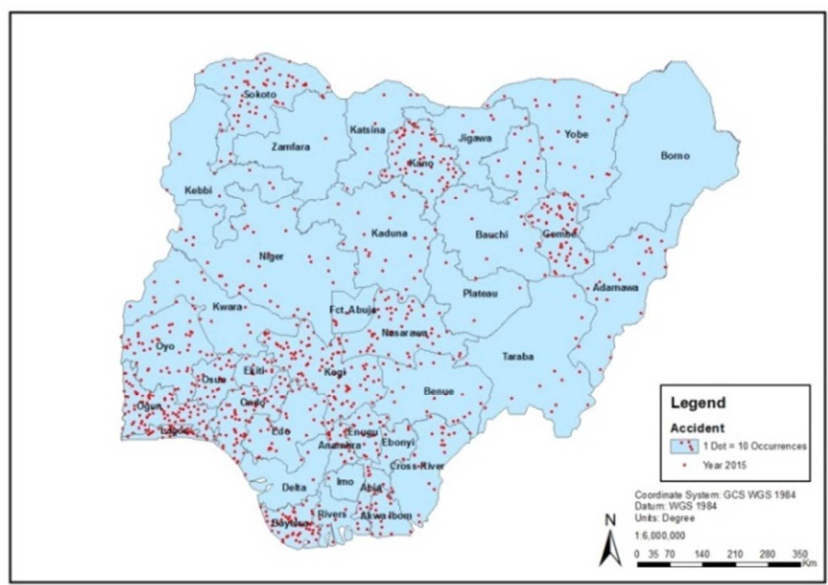

Figure 8. Dot map of road accident in Nigeria for 2015.

Analysis from the Nigeria road traffic accidents reports in 2014 depicts the total number or cases of recorded road accidents in 2014 across the 36 states and the federal capital territory. It should be noted that one dot represents 10 accident occurrences. $31 \%(25,427)$ of the total road accidents in the three years considered for this research occurred in 2014. Lagos State recorded the highest with 15.4\% of the total reported road crashes in 2014 followed by Ogun state with $8.2 \%$. These two states in the south-western part of
Nigeria had the highest reported road traffic accident cases because of their strategic locations, Lagos being the State that housed country's most functional international airport and seaport and as the Nigeria centre of commerce. Lagos has the highest number of industries and most densely populated city in Africa and Ogun States being the only an outlet State to and out of Lagos. The lowest case was recorded in Delta state with 212 cases which represent $0.8 \%$ of the country road accident cases in 2014.

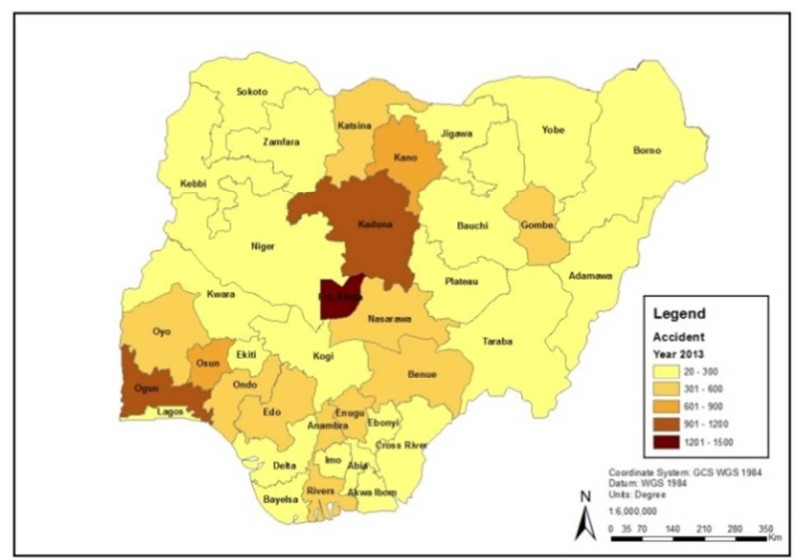

Figure 9. Road accident severity level thematic map for 2013

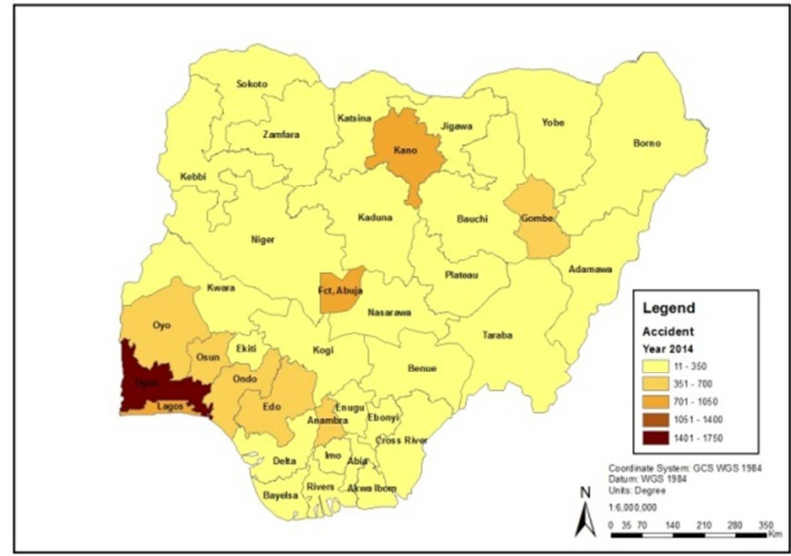

Figure 10. Road accident severity level thematic map for 2014.

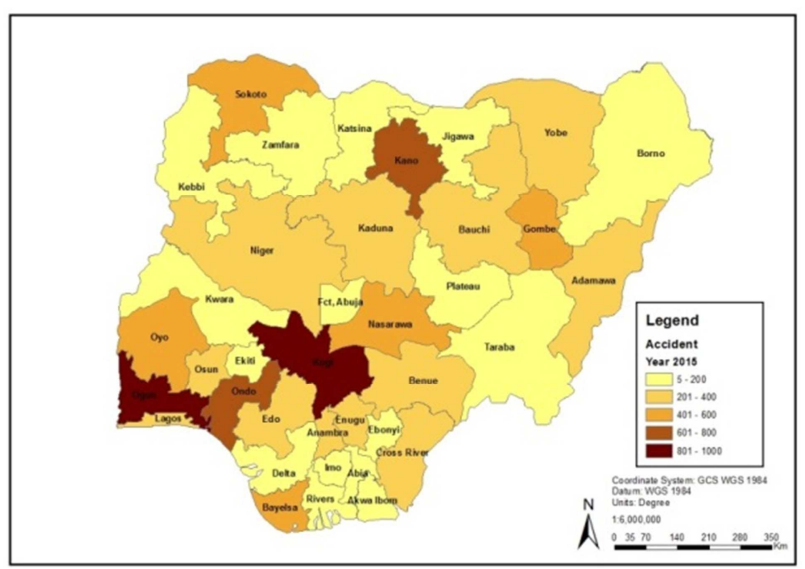

Figure 11. Road accident severity level thematic map for 2015. 
However, figures depict the stratification of the Nigeria states based on the severity of the recorded road traffic accident rate whereby Ogun and Kogi states in the southwest and north-central part of the country as the highest fatality States which ranges between 800 to 1000 fatality cases. This could be due to the fact that Ogun state is the first outlet state of Lagos city where all goods and passengers moving out and coming in to Lagos passes through. Kogi state on the other hand is the confluence state linking southwest, south-east and south-south regions of the country to the federal capital territory. Borno State recorded the lowest fatality rate in Nigeria as a result of the activities of Boko Haram insurgent group in this State which has completely left it deserted and paralyzed every other activity in this state. Regression Model

Table 3. Regression Model Summary.

\begin{tabular}{lllll}
\hline Model & R & R Square & Adjusted R Square & Std. Error of the Estimate \\
\hline 1 & $.779^{\mathrm{a}}$ & .606 & .213 & 492.929 \\
\hline
\end{tabular}

The data of recorded road traffic accident and the number of causalities resulted from this disaster for 2013, 2014 and 2015 was subjected to regression analysis for the future prediction of this disaster. The linear regression analysis models operate on the assumption that the relationship between one variable, dependent variable $y$ and other variables $\mathrm{x}$, as independent variables. The bivariate data express as $\left(\begin{array}{ll}x_{1} & y_{1}\end{array}\right)\left(\begin{array}{ll}x_{n} & y_{n}\end{array}\right)$, this is the sum of the square deviation about the line expressed as $\sum[\mathrm{y}-(\mathrm{a}+\mathrm{bx})]^{2}=\left[\mathrm{y}_{1}-(\mathrm{a}+\right.$ $\left.\left.\mathrm{bx}_{1}\right)\right]+\left[\mathrm{y}_{2}-\left(\mathrm{a}+\mathrm{bx}_{2}\right)\right]^{2}+\left[\mathrm{y}_{\mathrm{n}}-\left(\mathrm{a}+\mathrm{bx}_{\mathrm{n}}\right)\right]^{\mathrm{n}}$.

Here, the dependent variable is the numbers of causality and the independent variable is the recorded cases of road traffic accident. These can be expressed by the linear regression equation of the form:

$$
\mathrm{Y}=\mathrm{a}+\mathrm{bx}
$$

Where

$\mathrm{y}=$ dependent variable

$\mathrm{a}=$ the $\mathrm{y}$ intercept

$\mathrm{b}=$ slope of the regression line

$\mathrm{x}=$ independent variable

$\sum=$ error term that can enter the model

The result of the analysis reveals strong relationship between recorded cases of road accident in 2013, 2014 and 2015 and the number of casualties involved. Explanation from the regression analysis depicts y-dependent variable as the number of casualties owing to this disaster during these years and $\mathrm{x}$ as independent variables which is the total number of reported cases of road traffic accident in Nigeria in 2013, 2014 and 2015 respectively. The result thereof shows the strong positive relationship between the total number of recorded cases of road traffic accident and the number of death as a result of numbers of road accident recorded during these years with the coefficient of determinants which symbolizes the amount of variation explained by the regression model of $\mathrm{R}$ as 0.78 and $\mathrm{R}^{2}$ of 0.61 . The linear regression equation of $y=389.57+0.173 x$. Hence, the higher the number of reported cases of road crashes the higher the tendency of the person involved as well as the death toll and vice versa. The regression result show similarity with [7] that the higher the recorded road accidents, the higher the number of victims and fatality. This can be used to forecast the reduction in the death resulted from road traffic accident in the future due to the concerted efforts of government, road traffic law enforcement agencies, the road users and the general public towards bringing the occurrence of this disaster to acceptable minimal based on United Nations standard.

\section{Conclusions}

The invention of automobile engine has been a blessing to humanity as the most flexible mode of transportation. This study focused on the mapping and classification of the reported cases of road accident and fatality in Nigeria as the second highest cause of death in Nigeria. The study found out that the highest rate of road accidents occurred in 2013 with $36.9 \%$ and Ogun state, Lagos state and Federal capital territory were three locations with largest road crash cases and fatality with at least $6 \%$ each cases annually. This was as a result of the strategic positions of these states as the economic and administrative headquarters of the country.

The implementation of this research will provide detail spatial information of road accidents and fatality using map representation for the purpose of emergency management for the Federal Road Safety Commission (FRSC), National Emergency Agency (NEMA) and other stakeholders involved in road transportation management. It will also help the stakeholders involved to break down their operational system into smaller units that will drastically ameliorate this menace. Implementation of this research will also provide good map visualization platform which is the best way to enhance periodic road sensitization programme to the road users and the general public instead of the normal quoting of figures.

\section{Recommendations}

i. Enhance and sustenance of the periodic road accident sensitization programme to the road users and the general public.

ii. Mobile hospitals along the corridors should be improved, increased and sustained.

iii. Five years periodic repairing of roads due to our climatic factor (high rainfall and high temperature).

iv. Training and retraining of FRSC, NEMA, and VIO.

v. Upholding and improving electronic drivers' license process.

vi. Adoption of the use of satellite to monitor road accidents disaster for accurate locational information. 


\section{Conflict of Interest Statement and Data Availability}

I hereby confirmed that there is no conflicts of interest regarding this manuscript, the research was conducted by the three authors as reflected in the submission details and all the authors consented to publish this manuscript in this journal. There is no raw data submitted with this manuscript.

Thank you,

Emmanuel Dada.

\section{References}

[1] Adekunle, J. A., (2010). Road traffic accident deaths and socioeconomic development in Nigeria. Int. Rev. Bus. Soc. Sci. 1 (5): 47-60.

[2] Afolabi, J. A. and Gbadamosi, K. T. (2017). Road traffic crashes in Nigeria: causes and consequences. Transport and Logistics: the international journal; volume 17, issue 42.

[3] Agbonkhese, O., Yisa, G. L., Agbonkhese, E. G., Akanbi, D. O., Aka, E. O. and Mondigha, E. B., (2013). Road Traffic Accidents in Nigeria: Causes and Preventive Measures. Civil and Environmental Research, ISSN 2224-5790 (Paper) ISSN 2225-0514 (Online), Vol. 3, No. 13.

[4] Bruno, L. (1997). Transportation. In science and technology firsts. Detroit, Gale, 499-534.

[5] Chen, G., (2010). Road traffic safety in African countries status, trend, contributing factors, counter measures and challenges, international journal of injury control and safety promotion, 17 (4): 247-255.

[6] Favour Nnabugwu (2014). one million, two hundred thousand dead in road accidents - World Bank chief, Vanguard June 15.
[7] Federal Road Safety Commission (2015). Traffic digest, a transport digest publication of PRS department.

[8] Hancock, P. A., Lesch, M. and Simmons, L., (2003). The distraction effects of phone use during a crucial driving maneuverer, Accident analysis and prevention (35) 501-514.

[9] Lagarde, E. (2007). Road traffic injury is an escalating burden in Africa and deserves proportionate research efforts, PLoS Medicine, vol. 4 (6), pp. 967-71.

[10] International Road Federation Report on the state of accidents in the world (2015).

[11] Iyanda, A. E. (2018’0). Geographic analysis of road accidents severity index in Nigeria. International Journal of Injury Control and Safety Promotion, doi.org/10.1080/17457300.2018.1476387.

[12] National Bureau of Statistics (2015). Data of reported cases of road accidents in Nigeria from 2013-2015.

[13] Oladepo, O. and Brieger, R., (2006). Road traffic accidents: Applying the brake to a killing tree.

[14] Osayomi, T. (2013). Regional determinants of road traffic accidents in Nigeria: Identifying risk areas in need of intervention. African Geographical Review, 32 (1), 88-99.

[15] Osoro, M. E. Z., Oundo, J., Omolo, J., and Luman, E. (2011). Factors associated with severity of road traffic injuries, Thika, Kenya. Pan African Medical Journal, 8 (1), 20-27.

[16] Vitus N. U. (2014). Trends and patterns of fatal road accidents in Nigeria from 2006-2014, IFRA-Nigeria epapers series, 2014 N0 35.

[17] World Health Organization (2013). Report on Accidents in Africa.

[18] World Health Organization. (2017a). Decade of Action for Road Safety 2011-2020. Retrieved March 10, 2018, from http://www.who.int/road safety/decade_of_action/en/. 